\title{
Improvement of Mineral Oil Transformer Properties Using the Combinations of Nano and Micro Particles
}

\author{
Benyamin Abolfathi \\ Kermanshah University of Technology, \\ Department of Electrical Engineering, Kermanshah, IRAN.
}

\begin{abstract}
Liquid insulation plays an important role in power applications. Transformer oil as an insulation and coolant is a common liquid insulation that nowadays its dielectric and thermal properties can be improved by mixing various nano particles. In recent years, investigators have sought to improve electrical, thermal and physical properties (strength of breakdown voltage, thermal conductivity and viscosity) of the transformer oil only via nanoparticles. The nano silicon dioxide $\left(\mathrm{SiO}_{2}\right)$ particle is a semiconductive and hydrophilic particle that enhances the dielectric and some of the physical properties of the mineral oil. In this study, new combinations were prepared: mineral oil based on both nano and micro $\mathrm{SiO}_{2}$ particles with different concentrations (nano alone, micro alone and nano + micro compositions). The AC breakdown voltage, dielectric loss factor, viscosity, fire, flash and pour points were tested and measured. The AC breakdown voltage (an increasement about 1.68 times more than pure oil) and viscosity have been improved with adding $50 \%$ micro $+50 \%$ nano particles to mineral oil in sample 4 . Therefore, the value of breakdown strength for oil, containing both nano and micro $\mathrm{SiO}_{2}$, was found to be much greater than the values for pure oil. Fire and flash points didn't have a difference in sample 4 in comparison to the others, but cloud and pour points in samples $8(100 \%$ nano with concentration $0.08 \mathrm{~g} / \mathrm{l})$ and 4 were acceptable. The viscosity values for samples 0 (pure oil), $2(100 \%$ nano with concentration $0.01 \mathrm{~g} / \mathrm{l})$ and 4 were $12.63,8.54$ and 9.33 $\left(\mathrm{mm}^{2} / \mathrm{s}\right)$, respectively. So adding both micro and nano $\mathrm{SiO}_{2}$ to the transformer oil could improve some of the physical and electrical properties of the oil.
\end{abstract}

Index Terms - Transformer oil, Nano and micro $\mathrm{SiO}_{2}$ particles, $\mathrm{AC}$ breakdown voltage, Viscosity, Flash and fire points.

\section{INTRODUCTION}

TRANSFORMERS are the most critical equipment in high voltage (HV) networks, which should have enough insulating endurance during faults. Oils with low insulating endurance during faults may cause damages to the windings and solid insulations. Changing these parts is costly and imposes power outage to the network for a long time. The dielectric strength, the dielectric constant and the electrical conductivity are three most important properties of liquid dielectric. Mineral (Petroleum) oil has been used for power transformers since 1891. In recent years, nano fluids are considered as the most attractive materials for industrial, medical, mechanical, chemical and communication applications. The term "nano fluid" was invented by Choi at Argonne National Laboratory and refers to the combination in which a small amount of nano-sized materials is used. The modification in these studies is aimed at improving the dielectric properties to enhance the safety and stability of transformers during abnormal operation. Many experiments have been carried out on preparing nano oils by dispersing nanoparticles into insulating mineral or vegetable oils and measuring the electrical and thermal properties as presented below.

Example 1: Partial discharge is an important factor which increases streamer propagation and leads to the break down in insulation, so the dielectric losses generate heat and waste energy as well as money. The effect of various nano materials such as semi conductive and magnetic particles in transformer oils on electrical and thermal properties is experimented. The applied voltages in electrical test include DC, AC and impulse voltages. Haifa Jin and et al. investigated the effects of silica nano particle on the breakdown voltage, thermal conductivity, and viscosity with the moisture content level in mineral oil. The results showed that an addition of up to $0.02 \%$ silica nanoparticles improved AC breakdown voltage. Also up to a concentration of $0.1 \%$, silica nanoparticles had negligible effects on both viscosity and thermal conductivity of the mineral oil [1]. Different nano particles as nano - magnetite, Graphene oxide and silicone dioxide can be used in oil. Further, a variety of electrical tests has been carried out in previous studies, for example tests of the positive and negative $\mathrm{DC}$ withstand capability, the $\mathrm{AC}$ withstand capability, impulse voltage and partial discharge [2]. In [3], the impacts of adding semiconductive nanoparticles $\left(\mathrm{TiO}_{2}\right)$ on breakdown voltage and partial discharge (PD) characteristics of transformer oil were investigated. $\mathrm{TiO}_{2}$ increased $\mathrm{AC}, \mathrm{DC}$ and impulse breakdown voltage up to 1.2 times (compared to oil). Experimental results showed that partial discharge resistance, electron shallow trap density and charge decay rate were improved [4]. Du Yue-fan et al. clarified that $\mathrm{TiO}_{2}$ nanoparticle could enhance the dielectric performance of mineral oil [5]. Improvement in breakdown strength and relative permittivity in transformer oil consisting of $\mathrm{TiO}_{2}$ and $\mathrm{ZrO}_{2}$ nanoparticles has been confirmed in [6]. George Hwang et al. explained the electro dynamic 
process involved in the streamer propagation using magnetite nano particles[7]. By adding $\mathrm{AlN}$ and $\mathrm{Al}_{2} \mathrm{O}_{3}$ nanoparticles in transformer oil, a significant increase in thermal conductivity has been confirmed [8]. Reports of experimental data showed that adding less than one volume percent of nanoparticles can lead to enhancements in thermal conductivity [912]. The water content is estimated using moisture dynamic measurement in a power transformer, which allows online monitoring of water content [13]. In some new researches, dielectric nanoparticles have been used to reduce electric field. The nanoparticles can improve insulation materials' quality in order to be used in high electric field [14]. In addition, the hydrostatic pressure's effect on streamer propagation in transformer oil under pulsed voltages were investigated in [15]. In this study, mineral transformer oil was used as the base fluid. The viscosity of a fluid is an important physical property, which should be considered to determine the heat transfer rate of the oil. A fluid with low viscosity transmits heat well due to easy circulation. Furthermore, suitable viscosity means higher thermal conductivity which has a significant effect on dielectric strength of the transformer oil. Flash and fire, cloud and pour points (physical properties) measuring breakdown voltage, relative permittivity and dielectric losses test have been carried out on mineral oil with various nano- and micro particles` concentrations. At first, the samples were prepared at room temperature in the chemistry laboratory of the Kermanshah University of Technology (KUT), after which compatible samples were selected for subsequent testing as presented in section two. The physical and chemical properties of the best samples have been shown in section three. In section four, the breakdown voltage, tangent delta, resistivity and permittivity were discussed, and at the end, the conclusion was presented.

\section{PREPARATION OF THE SAMPLES}

The transformer oil (ARAD) meeting the IEC296 is the base fluid, which is widely used in distribution transformers in Iran. The $\mathrm{SiO}_{2}$ nano- and micro particles with particle size (diameter) between 11-13 nm, 1-5 $\mu \mathrm{m}$ used for the experiments, were purchased from Sigma-Aldrich. First, the silica nano and micro particles were weighed with a four decimal digit scale and the transformer oil was purified through an oil filter, then mixed together via the magnetic stirring method. The samples were stirred for 15 minutes and they were put in an ultrasonic bath for 2 hours at $25^{\circ} \mathrm{C}$ to enhance dispersion. Samples with different compositions of nano and micro silica $\left(\mathrm{SiO}_{2}\right)$ powder having oil are listed in Table 1.

Table 1. Used nano and micro weight and fractions for making the samples by checking their stability symbols

\begin{tabular}{c|c|c|c|c|c|c}
\hline $\begin{array}{c}\text { Number } \\
\text { of } \\
\text { samples }\end{array}$ & $\begin{array}{c}\text { Nano } \\
\text { particle } \\
(\%)\end{array}$ & $\begin{array}{c}\text { Micro } \\
\text { particle } \\
(\%)\end{array}$ & $\begin{array}{c}\text { Nano } \\
\text { particle } \\
\text { weight }(\mathrm{g})\end{array}$ & $\begin{array}{c}\text { Micro } \\
\text { particle } \\
\text { weight }(\mathrm{g})\end{array}$ & $\begin{array}{c}\text { Concentration } \\
(\mathrm{g} / \mathrm{L})\end{array}$ & $\begin{array}{c}\text { Chemial } \\
\text { stability } \\
\text { (Precipitate) }\end{array}$ \\
\hline 1 & 100 & 0 & 0.0040 & 0.0000 & 0.04 & Yes \\
2 & 100 & 0 & 0.0010 & 0 & 0.01 & No \\
3 & 75 & 25 & 0.0030 & 0.0010 & 0.04 & Yes \\
4 & 50 & 50 & 0.0005 & 0.0005 & 0.01 & No \\
5 & 0 & 100 & 0 & 0.0080 & 0.08 & Yes \\
6 & 75 & 25 & 0.0008 & 0.0003 & 0.01 & No \\
7 & 25 & 75 & 0.0003 & 0.0008 & 0.01 & Yes \\
8 & 100 & 0 & 0.0080 & 0 & 0.08 & No \\
9 & 50 & 50 & 0.0020 & 0.0020 & 0.04 & Yes \\
10 & 0 & 100 & 0 & 0.0040 & 0.04 & Yes \\
11 & 50 & 50 & 0.0060 & 0.0060 & 0.12 & Yes \\
12 & 25 & 75 & 0.0060 & 0.0060 & 0.08 & Yes \\
13 & 25 & 75 & 0.0030 & 0.0030 & 0.04 & Yes \\
14 & 75 & 25 & 0.0003 & 0.0003 & 0.01 & Yes \\
15 & 50 & 50 & 0.0040 & 0.0040 & 0.08 & Yes \\
16 & 100 & 0 & 0.0120 & 0 & 0.12 & Yes \\
17 & 25 & 75 & 0.003 & 0.0090 & 0.12 & Yes \\
18 & 0 & 100 & 0 & 0.0010 & 0.01 & Yes \\
\hline 19 & 0 & 100 & 0 & 0.0120 & 0.12 & 0.08 \\
\hline
\end{tabular}


The vast range of concentration was selected for getting accurate results. The precipitate time for the samples was measured during 2 months and some of them were precipitated in one day or more than a few days, but there was no observations of precipitate in five samples after 5 months (until now). Detailed properties of the $\mathrm{SiO}_{2}$ particles are visible in Table 2 .

Table 2. Units and corresponding symbols

\begin{tabular}{c|c}
\hline Parameters & Values \\
\hline Purity & $99+\%$ \\
Average Particle Size & $11-13 \mathrm{~nm}, 1-5 \mu \mathrm{m}$ \\
Color & White \\
Density & $2.1 \mathrm{~g} / \mathrm{cm} 3$ \\
\hline
\end{tabular}

At first, the compositions were weighted with a four digit scale measurement in gr unit, then purification was done with two paper filters. Dispersing the samples using a magnetic stirrer and an ultrasonic bath were done in the laboratory.

\section{CHEMICAL AND PHYSICAL PROPERTIES}

Chemical and physical properties of transformer oil impress electrical properties. Based on the impressive points, the quality of the oil and its longevity can be changed. Chemical properties are related to the main electrical items, which cause oxidation, sludge and gas production, transformer oil corrosion and ageing. Precipitate in the oil is the first item that must be carried out by experimental tests. Chemical stability depends on the precipitates time and agglomeration, too. Physical properties of the transformer oil include: viscosity, water content, fire and flash points, cloud and pour points and thermal conductivity. In this research, chemical stability was investigated at first and then viscosity, flash, fire, cloud and pour points were measured. All of the samples were prepared at the same temperature and condition. For checking the chemical stability, precipitate time was measured in the 20 samples during 2 months. There were 5 stable samples with no sedimentations. Sample 2 (100\% nano particle), sample 4 ( $50 \%$ micro $+50 \%$ nano particles), sample $6(75 \%$ nano $+25 \%$ micro particles), sample $18(100 \%$ micro particle) with 0.01 Concentration $(\mathrm{g} / \mathrm{L})$ and sample 8 $(100 \%$ nano) with 0.08 Concentration $(\mathrm{g} / \mathrm{L})$ were the best. They were stable until being heated (drying) for 2 hours in the oven at a temperature above $80^{\circ} \mathrm{C}$.

\subsection{VISCOSITY}

Viscosity is an important physical property which has an influence on both electrical properties (it has a strong impact on breakdown voltage (BD) and the heat transfer performance of transformer oil. Low viscosity (in a specific range) can improve the $\mathrm{BD}$ voltage values and thermal property. To determine the effect of $\mathrm{SiO}_{2}$ nanoand micro particles' composition, the viscosity of three samples was measured using a viscometer according to standard ISO 3104/ASTM D 445 with standard error $\pm 0.30 \%$. The viscosity values at $40^{\circ} \mathrm{C}$ for samples 0,2 and 4 were $12.63,8.54$ and $9.33\left(\mathrm{~mm}^{2} / \mathrm{s}\right)$, respectively. It can be concluded that samples 2 and 4 had lower viscosity into pure oil, in other words adding nano or both nano and micro $\mathrm{SiO}_{2}$ particle to transformer oil could decrease the viscosity and enhance thermal conductivity.

\subsection{FIRE AND FLASH POINTS}

The flash point is the temperature at which oil produces so much vapour that this vapour, when mixed with air, forms an ignitable mixture and generates a momentary flash on the application of flame under prescribed conditions [16]. Fire and flash points were measured by Cleveland open cup tester according to standard ASTM D 92 for samples 0,2 and 4. Although using a closed cup tester is a safe and reliable way to measure fire and flash points, there was only an open cup tester available in our laboratory.

Table 3. The flash and fire points of the samples measured by Cleveland open cup
\begin{tabular}{c|c|c}
\hline Samples & Flash point $\left({ }^{\circ} \mathrm{C}\right)$ & Fire point $\left({ }^{\circ} \mathrm{C}\right)$ \\
\hline 0 & 142 & 144 \\
2 & 140 & 142 \\
4 & 146 & 149 \\
\hline
\end{tabular}

The results in Table 3 showed that adding nano or both nano and micro $\mathrm{SiO}_{2}$ particles to transformer oil did not make a sensible change in flash and fire points. 


\subsection{CLOUD AND POUR POINT}

One of the other important factors related to the physical properties is the pour point. Physical properties of the transformer oil change in cold weather, which also causes new electrical and insulating properties. In this study, the cloud and pour points were carried out using the Seta cloud and pour point bath in the laboratory at room temperature according to the ASTM D 97 standard. At a low pour point, viscosity increases, which means bad circulation and a disadvantage for transformer oil. Results showing cloud and pour points for four samples have been represented in Table 4.

Table 4. Cloud and pour points` results according to standard ASTM D 97

\begin{tabular}{c|c|c|c}
\hline Samples & $\begin{array}{c}\text { End Time (beginning } \\
\text { time at } 14: 25)\end{array}$ & $\begin{array}{c}\text { Cloud point } \\
\left({ }^{\circ} \mathrm{C}\right)\end{array}$ & $\begin{array}{c}\text { Pour } \\
\text { point }\left({ }^{\circ} \mathrm{C}\right)\end{array}$ \\
\hline 0 & $15: 04$ & -19 & -21 \\
2 & $15: 08$ & -15 & -18 \\
4 & $15: 15$ & -24 & -27 \\
8 & $14: 57$ & -25 & -28 \\
\hline
\end{tabular}

The results showed that cloud and pour points decreased in sample $2(100 \%$ nano with $0.01 \mathrm{~g} / \mathrm{l}$ concentration $)$ and increased in sample $4(50 \%$ nano $+50 \%$ micro $)$ and 8 (100\% nano with $0.08 \mathrm{~g} / 1$ concentration), therefore choosing a suitable concentration of nano or both nano and micro particles is very important.

\section{ELECTRICAL PROPERTIES}

Mineral oil is widely used in HV transformers and power application. The insulating property is the most important factor in power system equipment to prevent faults and instability. The electrodynamic behavior of oil with the presence of dispersed nano- and micro silica particles has been considered to exhibit different electrical breakdown characteristics, which depend on the relaxation time constant and streamer growth. If the nano and micro charge relaxation time constants be shorter than their streamer growth time, the electrodynamic behavior of the liquid insulation would change the breakdown voltage. The spherical nano (micro) particle of an arbitrary material with radius $\mathrm{R}$, permittivity $\varepsilon_{2}$, and conductivity $\sigma_{2}$ in transformer oil with the conductivity of $\sigma_{1}(\mathrm{~S} / \mathrm{m})$ and permittivity $\varepsilon_{1}$ is shown in Figure 1 when $\varepsilon_{0}=8.85 \times 10^{-12} \mathrm{~F} / \mathrm{m}$. nano and micro particles can deviate electric field distribution from $\mathrm{z}$ - axis direction.

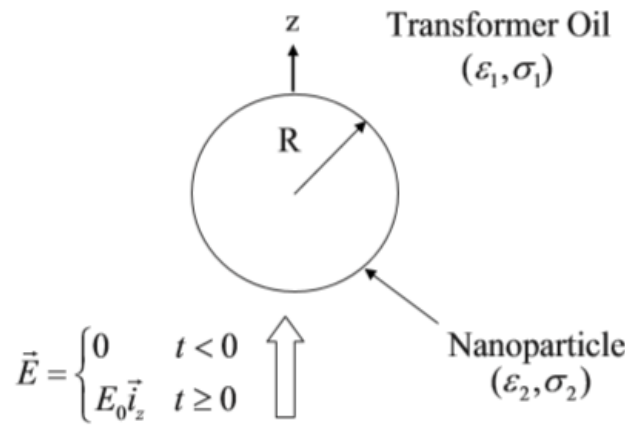

Figure 1. Nanoparticle of an arbitrary material [17]

The time dependent electric fields (radial and polar components) in oil and around nanoparticle are [18-20]:

$E_{r 0}(r, \theta)=E_{0}\left\{1+\frac{2 R^{3}}{r^{3}} Y_{c} \exp \left(-\frac{t}{\tau_{r}}\right)+\frac{2 R^{3}}{r^{3}} \sum_{c}[1-\right.$

$\left.\left.\exp \left(-\frac{t}{\tau_{r}}\right)\right]\right\} \cos \theta$

$E_{\theta 0}(r, \theta)=E_{0}\left\{-1+\frac{R^{3}}{r^{3}} Y_{c} \exp \left(-\frac{t}{\tau_{r}}\right)+\frac{R^{3}}{r^{3}} \sum_{c}[1-\right.$

$\left.\left.\exp \left(-\frac{t}{\tau_{r}}\right)\right]\right\} \sin \theta$

where the charge relaxation time constant $\tau_{\mathrm{r}}$ for the nano (micro) or composite transformer oil system is:

$$
\begin{gathered}
\tau_{r}=\frac{2 \epsilon_{1}+\epsilon_{2}}{2 \sigma_{1}+\sigma_{2}} \\
Y_{c}=\frac{\epsilon_{2}-\epsilon_{1}}{2 \epsilon_{1}+\epsilon_{2}}
\end{gathered}
$$




$$
\sum_{c}=\frac{\sigma_{2}-\sigma_{1}}{2 \sigma_{1}+\sigma_{2}}
$$

According to Table 5 and for Nano silica particle with diameter $12 \mathrm{~nm}$, the parameters were obtained as: $\tau_{r}=$ $3.46 * 10^{9}, Y_{c}=0.664, \sum_{c}=0.985$. Then radial and polar components of electric field are:

$$
\begin{aligned}
E_{r 0}(r, \theta)=E_{0}\{1 & \left.+\frac{286.8}{r^{3}} \exp \left(-\frac{t}{3.46 * 10^{9}}\right)+\frac{282.5}{r^{3}} *\left[1-\exp \left(-\frac{t}{3.46 * 10^{9}}\right)\right]\right\} \cos \theta E_{\theta 0}(r, \theta) \\
& =E_{0}\left\{-1+\frac{143.4}{r^{3}} \exp \left(-\frac{t}{3.46 * 10^{9}}\right)+\frac{212.76}{r^{3}}\left[1-\exp \left(-\frac{t}{3.46 * 10^{9}}\right)\right]\right\} \sin \theta
\end{aligned}
$$

Based on the above equations (these components are related to the nano particles, there are more than four equations for micro, buble, oil, dust and salt particles too), the electric field in the oil depends on relative permittivity, conductivity and charge relaxation time. Nano- and micro particles in oil deviate electric field lines from direct route (z-axis) which can decrease field density and distribute the lines. These fields exert various forces, causing particles to move and causing traps to move as well, which can delay streamer propagation and increase breakdown voltage. Some of the electrical and thermal properties of $\mathrm{SiO}_{2}$ nano particles have been presented in Table 5.

Table 5. Electrical and thermal properties of Silica Nano particle

\begin{tabular}{c|c}
\hline Parameters & Values \\
\hline Density $\left(\mathrm{g} / \mathrm{cm}^{3}\right)$ & 2.18 \\
Electric conductivity $(\mathrm{S} / \mathrm{m})$ & $1.4 \mathrm{e}^{-9}$ \\
Relative dielectric constant & 3.8 \\
Relaxation time $(\mathrm{s})$ & $5.12 \mathrm{e}^{-2}$ \\
Dielectric strength $(\mathrm{kV} / \mathrm{mm})$ & $\ldots \ldots$ \\
Thermal conductivity $\left(\mathrm{Wm}^{-1} \mathrm{~K}^{-1}\right)$ at $20{ }^{\circ} \mathrm{C}$ & 1.38 \\
Thermal expansion coefficient $\left(\mu \mathrm{mm}^{-1} \mathrm{~K}^{-1}\right)$ & 30 \\
Specific heat $\left(\mathrm{J} \mathrm{kg}^{-1} \mathrm{~K}^{-1}\right)$ & 670 \\
\hline
\end{tabular}

A force related to the electric field directs toward suspended particles (nano and micro $\mathrm{SiO}_{2}$ ) in oil. The force moves the particles to the areas of maximum stress according to the equation (6) which affects electric field distribution in the areas and changes electron movement path.

$$
F=\frac{1}{2} r^{3} \frac{\left(\epsilon_{2}-\epsilon_{1}\right)}{2 \epsilon_{1}+\epsilon_{2}} \operatorname{grad} E_{2}
$$

Affected by the movement of nano- and micro particles, traps move, as well. Electrons falling into the traps prevent chain (bridge) formation in oil, which improves the transformer oil`s electrical properties, especially its breakdown voltage (BD). While both micro and nano particles are suspended in oil, there are no small spaces for forming a chain of free electrons and they make delay in streamer propagation. Particles move into the region of high stress due to the viscous force of liquid, too. Viscous force, described by Stoke's relation, depends on the viscosity of liquid, the radius and the velocity of the particles [21].

\subsection{BREAKDOWN VOLTAGE TEST}

The AC BD voltage of the samples was measured according to the IEC60156 standard at $60 \mathrm{~Hz}$ frequency. Two spherical electrodes were made from brass with a gap distance of $2.5 \mathrm{~mm}$ and the rate of voltage rise was chosen as $2 \mathrm{kV} / \mathrm{s}$. The results in Table 6 contain an average of six times measured BD, standard deviation and standard deviation / average values. Sample 0 is the pure mineral oil. 
Table 6. The Break Down Voltage of various samples

\begin{tabular}{c|c|c|c|c}
\hline Samples & $\begin{array}{c}\text { Average BD } \\
\text { Voltage } \\
(\mathrm{Kv})\end{array}$ & $\begin{array}{c}\text { Standard } \\
\text { deviation } \\
(\mathrm{Kv})\end{array}$ & $\begin{array}{c}\text { Standard } \\
\text { deviation / } \\
\text { Average }(\%)\end{array}$ & $\begin{array}{c}\text { Temperature } \\
\left({ }^{\circ} \mathrm{C}\right)\end{array}$ \\
\hline 0 & 33.7 & 11.6 & 34.3 & 27 \\
2 & 55.5 & 8.9 & 16.0 & 31 \\
4 & 56.9 & 3.3 & 5.8 & 30 \\
6 & 53.7 & 5.6 & 10.5 & 29 \\
8 & 45.2 & 2.8 & 6.1 & 31 \\
18 & 52.3 & 4.9 & 9.4 & 29 \\
\hline
\end{tabular}

The horizontal axis in Figure 2 is the number of samples and the vertical one is the average break down voltage values, the average breakdown voltage is the highest amount $(55.5 \mathrm{kV})$.

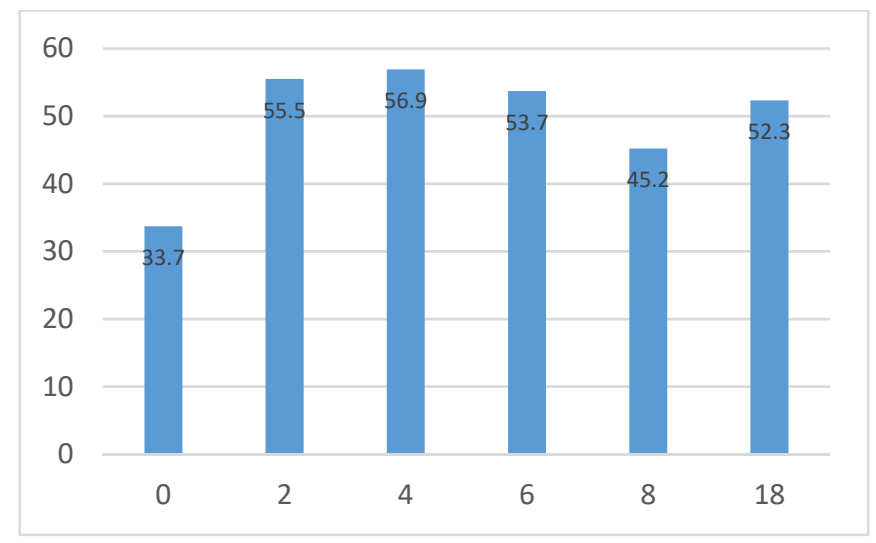

Fig 2. Average breakdown voltage for 6 samples

Adding both micro and nano (50\% Micro $+50 \% \mathrm{Nano}$ ) $\mathrm{SiO}_{2}$ powder to oil, increased $\mathrm{BD}$ voltage values into the other compositions. AC breakdown strength was greatly affected by the moisture content in oil. The breakdown process occurs due to the fast motion of electrons in the form of streamer propagation. The higher BD voltage is a result of the changed electrodynamics of the streamers within the oil due to the presence of nano- and micro structures. These particles with high dielectric constant, change the permittivity of the oil which decreases the streamer propagation velocity and increases breakdown strength. The value of the breakdown strength increased significantly from 13.48 at pure oil to $22.76 \mathrm{kV} / \mathrm{mm}$ at sample 4 . It is shown that the breakdown strength improved by adding both micro- and nano particles.

\subsection{DIELECTRIC PROPERTY}

Polar components strongly influence the dissipation factor, which is an essential parameter. The dielectric dissipation factor is equal to the tangent of loss angle for dielectrics and is a good tool to indicate the quality of insulation [22]. Relative permittivity depends on the internal structure of oil and its polarization under electric field, which has relation with the dissipation factor according to equation 8 . The loss factor $(\tan \delta)$ has a direct relevance to electrical conductivity $(\mathrm{k})$ and has an inverse relevance to permittivity $\left(\varepsilon_{\mathrm{r}}\right)$.

$$
\tan \delta=\frac{k}{\varepsilon_{r} \varepsilon_{0} \omega}
$$

For temperature-compensated (TC) values:

$$
\tan \delta_{T C}=\frac{k_{T C}}{\varepsilon_{r T C} \varepsilon_{0} \omega}
$$

The dissipation factor and resistivity were measured for the samples according to the EC 60247-2004 standard. Relative permeability of the samples can be compared to pure oil according to equation 7 in Table $7\left(\varepsilon_{\mathrm{r}} \mathrm{n}, \varepsilon_{\mathrm{r}} 0\right.$ are the relative permeability of the samples $2,4,6,8,18$ and zero sample (pure oil), respectively). 
Table 7. The dielectric properties of various samples

\begin{tabular}{c|c|c|c}
\hline Samples & Tan $\delta$ at $90^{\circ} \mathrm{c}$ & Resistivity $(\mathrm{G} \Omega \mathrm{m})$ & $\varepsilon_{\mathrm{r}} \mathrm{n} / \varepsilon_{\mathrm{r} 0}$ \\
\hline 0 & 0.004 & 137 & 1 \\
2 & 0.002 & 116 & 2.36 \\
4 & 0.002 & 92 & 2.97 \\
6 & 0.002 & 91 & 3 \\
8 & 0.001 & 189 & 2.89 \\
18 & 0.002 & 89 & 3.07 \\
& & & \\
\hline
\end{tabular}

The lowest dissipation factor was for sample 8 and then 4, 6 and 18, respectively. The value of tangent delta (dissipation factor) at $90^{\circ} \mathrm{C}$ was 0.002 , resistivity was $92 \mathrm{G}$-ohm and the permittivity increased 2.97 times more than pure oil in sample 4. Of course sample 8 showed the best insulation property (low loss factor and high resistivity) rather than the other samples but, for a suitable oil, the improvement of all chemical, physical and electrical properties is important. Based on the results, adding nano, micro or both nano and micro $\mathrm{SiO}_{2}$ particles changed the transformer oil quality positively. In all the samples, relative permittivity was increased and the loss factor was decreased. The amount of nano- and micro particles should be noticed as an important attention point and could be classified by additional experiments.

\section{CONCLUSIONS}

The electrical and some of the chemical and physical properties of mineral transformer oil with new combinations of both nano and micro particles of $\mathrm{SiO}_{2}$ were investigated in this study. The results showed a considerable improvement in new combinations which could increase the quality of insulation oil. According to the experiment planning, 5 samples were chosen for different tests from 20 samples. The value of viscosity, cloud and pour points were improved in sample 4, but there was no significant improvements regarding fire and flash points. The value of the breakdown strength increased significantly from 13.48 at pure oil to $22.76 \mathrm{kV} / \mathrm{mm}$ at sample 4 , as well. The loss factor at $90^{\circ} \mathrm{C}$ and resistivity had the best values in sample 8 , but the other properties were not as good as these factors, so sample 4 was a suitable candidate for good insulation. Therefore, it is clear that by adding micro particles to nano oil, the quality of transformer oil changed positively, but the amount and concentration of this addition is also of utmost importance.

\section{REFERENCES}

Periodicals

[1] H. Jin, T. Andritsch, I. A. Tsekmes, R. Kochetov, P. H. F. Morshuis, J. J. Smit, "Properties of Mineral Oil based Silica Nanofluids". IEEE Transactions on Dielectrics and Electrical Insulation, 2014. 21(3): p. $1100-1108$.

[2] Andrea Cavallini, R. Karthik and Fabrizio Negri, "The Effect of Magnetite, Graphene Oxide and Silicone Oxide Nanoparticles on Dielectric Withstand Characteristics of Mineral Oil”. IEEE Transactions on Dielectrics and Electrical Insulation, 2015. 22(5): p. $2592-2600$

[3] Yuefan Du, Yuzhen Lv, Chengrong Li, Mutian Chen, Yuxiang Zhong, Jianquan Zhou, Xiaoxin Li and You Zhou, "Effect of Semiconductive Nanoparticles on Insulating Performances of Transformer Oil". IEEE Transactions on Dielectrics and Electrical Insulation, 2012. 19(3): p. $770-776$.

Papers Presented at Conferences (unpublished)

[4] Diaa-Eldin A. Mansour et al, "Effect of titania nanoparticles on the dielectric properties of transformer oil-based nanofluids". Electrical Insulation and Dielectric Phenomena (CEIDP), 2012 Annual Report Conference on, 2012. Montreal, QC, Canada, IEEE.

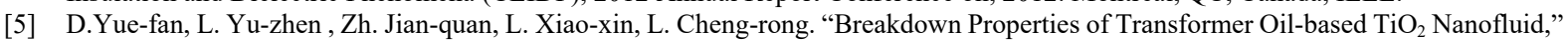
2010 Annual Report Conference on Electrical Insulation and Dielectric Phenomena.

[6] Yu-zhen Lv, Xiao-xin Li, Yue-fan Du, Fo-chi Wang and Cheng-rong Li. "Preparation and breakdown Strength of TiO 2 Fluids Based on Transformer Oil," 2010 Annual Report Conference on Electrical Insulation and Dielectric Phenomena.

Conference Proceedings and Reports (published)

[7] J.George Hwang, Markus Zahn, Francis M.O’Sullivan, Leif A.A.Pettersson, Olof Hjortstam,and Rongsheng Liu. "Electron Scavenging by Conductive Nanoparticles in Oil Insulated Power Transformers," 2009 Electrostatics Joint Conference-Paper 1.1:1-12.

[8] David C.Venerus, and Jacopo Buongiarno, "Viscosity measurements on colloidal dispersions (nanofluids) for heat transfer applications", Applied Rheology, Volume 20- Issue-4, 2009.

[9] C. Zhi, Y. Xu, Y. Bando and D. Golberg, "Highly Thermoconductive Fluid with Boron Nitride Nanofillers", Amer. Chem. Soc. (ACS) Nano Vol. 5, pp. 6571-6577, 2011.

[10] S. S. Botha, P. Ndungu and B.J. Bladergroen, "Physicochemical Properties of Oil-Based Nanofluids Containing Hybrid Structures of Silver Nanoparticles Supported on Silica”, Ind. Eng. Chem. Res., Vol. 50, pp. 3071-3077, 2011.

[11] T.T. Baby and R. Sundara, "Synthesis and Transport Properties of Metal Oxide Decorated Graphene Dispersed Nanofluids", J. Phys. Chem. C, Vol. 115, pp. 8527-8533, 2011.

[12] J.A. Eastman, S.U.S. Choi, S. Li, W. Yu and L.J. Thompson, “Anomalously Increased Effective Thermal Conductivities of Ethylene Glycol-Based Nanofluids Containing Copper Nanoparticles”, Appl. Phys. Lett., Vol. 78, pp. 718-720, 2001.

[13] V. Sarfi, S. Mohajeryami and A. Majzoobi, "Estimation of water content in a power transformer using moisture dynamic measurement of its oil”, High Volt, Vol. 2, Iss. 1, pp. 11-16, 2017. 


\section{Periodicals}

[14] J. A. Davis, "Energy Density Limits of Multiphase Composites With Dielectric Nanoparticles", IEEE transaction on nanotechnology, Vol. 17, No. 2, March 2018.

Papers Presented at Conferences (unpublished)

[15] T. Wang et al., "Effect of hydrostatic pressure on the impulse breakdown characteristics of transformer oil", Power Modulator and High Voltage Conference (IPMHVC), 2016 IEEE International, 2016.

Books

[16] J.C. Maxwell, "A Treatise on Electricity and Magnetism, 2nd ed", Clarendon Press: Oxford, 1881.

[17] BHEL, Bhopal, Tata Mcgraw-Hill, "Transformers", Publishing Company Limited, Seventh Reprint, 1995.

Conference Proceedings and Reports (published)

[18] J.George Hwang, Markus Zahn, Francis M.O’Sullivan, Leif A.A.Pettersson, Olof Hjortstam,and Rongsheng Liu. "Electron Scavenging by Conductive Nanoparticles in Oil Insulated Power Transformers", 2009 Electrostatics Joint Conference-Paper 1.1:1-12.

Theses (MS) and Dissertations (PhD)

[19] F. M. O’Sullivan, Ph.D. thesis, Massachusetts Institute of Technology, 2007.

Books

[20] M. Zahn, "Electromagnetic Field Theory: A Problem Solving Approach”, Robert E. Krieger, Malabar, Florida, 2003.

[21] J. R. Melcher, "Continuum Electromechanics MIT Press", Cambridge, Massachusetts, 1981.

[22] Alston, "High Voltage Technology", Oxford University Press, 1968.

[23] V. Sarfi, S. Mohajeryami and A. Majzoobi, "Estimation of water content in a power transformer using moisture dynamic measurement of its oil”, High Volt, Vol. 2, Iss. 1, pp. 11-16, 2017.

Periodicals

[24] J. A. Davis, "Energy Density Limits of Multiphase Composites With Dielectric Nanoparticles", IEEE transaction on nanotechnology, Vol. 17, No. 2, March 2018.

Papers Presented at Conferences (unpublished)

[25] T. Wang et al., "Effect of hydrostatic pressure on the impulse breakdown characteristics of transformer oil", Power Modulator and High Voltage Conference (IPMHVC), 2016 IEEE International, 2016.

Books

[26] J.C. Maxwell, “A Treatise on Electricity and Magnetism, 2nd ed”, Clarendon Press: Oxford, 1881.

[27] BHEL, Bhopal, Tata Mcgraw-Hill, “Transformers”, Publishing Company Limited, Seventh Reprint, 1995.

Conference Proceedings and Reports (published)

[28] J.George Hwang, Markus Zahn, Francis M.O’Sullivan, Leif A.A.Pettersson, Olof Hjortstam,and Rongsheng Liu. "Electron Scavenging by Conductive Nanoparticles in Oil Insulated Power Transformers", 2009 Electrostatics Joint Conference-Paper 1.1:1-12.

Theses (MS) and Dissertations (PhD):

[29] F. M. O'Sullivan, Ph.D. thesis, Massachusetts Institute of Technology, 2007.

Books

[30] M. Zahn, "Electromagnetic Field Theory: A Problem Solving Approach", Robert E. Krieger, Malabar, Florida, 2003.

[31] J. R. Melcher, "Continuum Electromechanics MIT Press", Cambridge, Massachusetts, 1981.

[32] Alston, "High Voltage Technology", Oxford University Press, 1968. 